\title{
DEVELOPMENT OF AN AdVANCED Two-MiCron TRIPLE-PULSE IPDA LIDAR FOR CARBon Dioxide AND WATER VAPOR MEASUREMENTS
}

\author{
Mulugeta Petros ${ }^{1}$, Tamer F. Refaat ${ }^{1}$, Upendra N. Singh ${ }^{1}$, Jirong $\mathrm{Yu}^{1}$, Charles Antill ${ }^{1}$, \\ Ruben Remus ${ }^{1}$, Bryant D. Taylor ${ }^{2}$, Teh-Hwa Wong ${ }^{2}$, Karl Reithmaier ${ }^{2}$, Jane Lee $^{2}$, \\ Syed Ismail $^{3} \&$ Kenneth J Davis \\ ${ }^{1}$ NASA Langley Research Center, Hampton, VA 2381, USA, * mulugeta.petros-1@nasa.gov \\ ${ }^{2}$ Science Systems and Applications, Inc., Hampton, VA 23666, USA, \\ ${ }^{3}$ Analytical Services and Materials, Inc., Hampton, VA 23666, USA, \\ ${ }^{4}$ Pennsylvania State University, University Park, PA 16802, USA
}

\begin{abstract}
An advanced airborne triple-pulse 2- $\mu \mathrm{m}$ integrated path differential absorption (IPDA) lidar is under development at NASA Langley Research Center that targets both carbon dioxide $\left(\mathrm{CO}_{2}\right)$ and water vapor $\left(\mathrm{H}_{2} \mathrm{O}\right)$ measurements simultaneously and independently. This lidar is an upgrade to the successfully demonstrated $\mathrm{CO}_{2} 2-\mu \mathrm{m}$ doublepulse IPDA. Upgrades include high-energy, highrepetition rate $2-\mu \mathrm{m}$ triple-pulse laser transmitter, innovative wavelength control and advanced $\mathrm{HgCdTe}$ (MCT) electron-initiated avalanche photodiode detection system. Ground testing and airborne validation plans are presented.
\end{abstract}

\section{INTRODUCTION}

Understanding the process of $\mathrm{CO}_{2}$ exchange in the context of global climate change has become the topic of vital importance to the scientific community. Knowledge of the spatial and temporal distribution of $\mathrm{CO}_{2}$ sources and sinks, and transport in a global scale is crucial to predict and possibly manage the carbon cycle process. In response to these challenges, laser-based active remote sensing instruments are being developed at NASA Langley Research Center (LaRC) [1-2]. Active remote sensors have a number of advantages including night, seasonal, high latitude, and tropical ecosystems measurements. LaRC researchers have envisioned a $2-\mu \mathrm{m}$ triplepulse integrated path differential absorption (IPDA) lidar that can measure atmospheric column concentrations of $\mathrm{CO}_{2}$ and $\mathrm{H}_{2} \mathrm{O}$ simultaneously and independently. This lidar operates on both ground and airborne platforms. The 2- $\mu \mathrm{m}$ wavelength chosen for this instrument provides attractive spectroscopic features that include strong $\mathrm{CO}_{2}$ absorption, low temperature dependence and minor interference from other atmospheric gases. In addition, the $2-\mu \mathrm{m}$ favors low tropospheric weighting functions that focus on $\mathrm{CO}_{2}$ near-surface dynamics. Pulsed laser operation enables a direct measurement of absorption column length. This paper presents the technical methodology and technology progress for this $2-\mu \mathrm{m}$ IPDA lidar.

Utilizing meteorological data, this unique $2-\mu \mathrm{m}$ triple-pulse IPDA lidar is used to measure atmospheric dry-air column mixing ratios of $\mathrm{CO}_{2}$ $\left(\mathrm{XCO}_{2}\right)$ and $\mathrm{H}_{2} \mathrm{O}\left(\mathrm{XH}_{2} \mathrm{O}\right)$ with projected precision of $0.2 \%$ and $0.5 \%$, respectively [1]. Three wavelengths are carefully selected to achieve independent and simultaneous measurements of $\mathrm{CO}_{2}$ and $\mathrm{H}_{2} \mathrm{O}$ as shown in figure 1 . The first and second, $\lambda_{1}$ and $\lambda_{2}$, are strongly absorbed by $\mathrm{H}_{2} \mathrm{O}$ and $\mathrm{CO}_{2}$, respectively. The third, $\lambda_{3}$, is tuned where both have low absorption. The ratio of transmitted energy, E, and received signals power, $\mathrm{P}$, reflected off a hard target for on- and off-line wavelength provides the measured differential optical depth, dOD, according to

$$
d O D=\ln \left[\frac{P_{o f f} \cdot t_{o f f}}{E_{o f f}} / \frac{P_{o n} \cdot t_{o n}}{E_{o n}}\right]
$$

which is the primary IPDA product, where $t$ is the hard target return pulse width. Meteorology and spectroscopic data base (HITRAN) define the range-based weighting function from

$$
W F(r)=\Delta \sigma(r) \cdot N_{d r y}(r)
$$

where $\Delta \sigma$ is the differential absorption cross section, $\mathrm{N}_{\mathrm{dry}}$ is the dry-air number density and $\mathrm{r}$ is the range. The dry-air weighted-column mixing ratio, $X$, is given by 

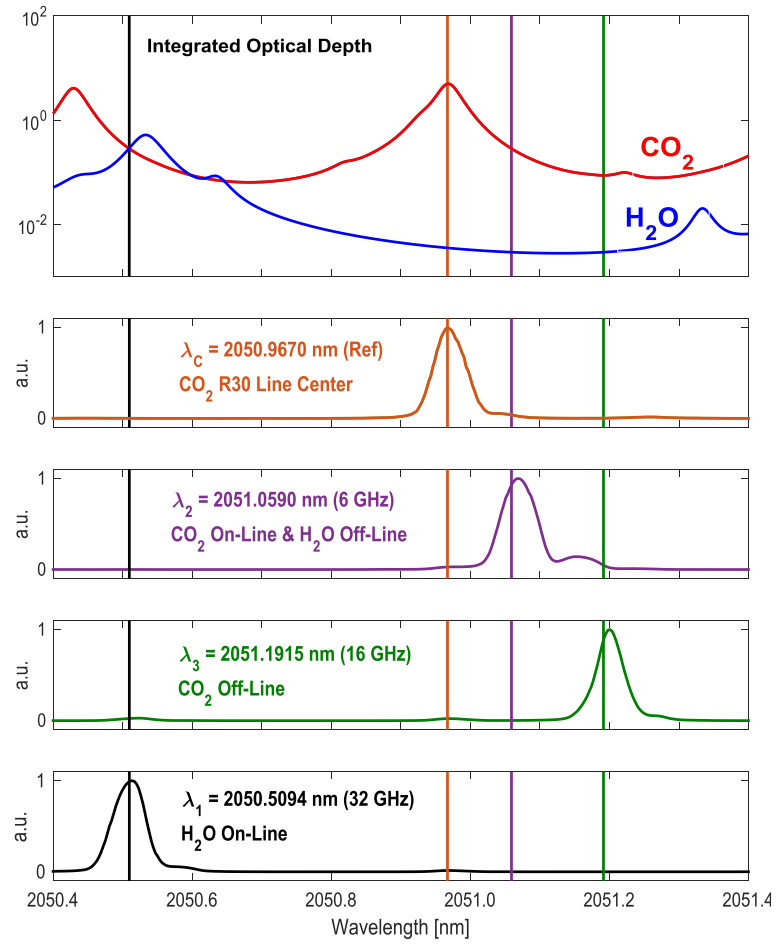

Figure 1 Integrated optical depth spectra of $\mathrm{CO}_{2}$ and $\mathrm{H}_{2} \mathrm{O}$ as compared to the selected 2- $\mu$ m triple-pulse IPDA operating wavelengths [1] (top). Wavelengths are tuned and locked with respect to $\mathrm{CO}_{2} \mathrm{R} 30$ line center (bottom). Observed broadening is due to spectrometer resolution.

$$
X=d O D / \int_{R_{A}}^{R_{G}} W F(r) \cdot d r
$$

where $\mathrm{R}_{\mathrm{A}}$ and $\mathrm{R}_{\mathrm{G}}$ are the instrument altitude and target elevation, respectively.

\section{TECHNOLOGY DEVELOPMENT}

In this IPDA the transmitter emits three pulses separated by $200 \mu$ s at $50 \mathrm{~Hz}$ repetition rate. The IPDA transmitted pulses time separation maximizes the measured column volume-overlap. These pulses are seeded at selected wavelengths that are generated by an offset with respect to the $\mathrm{CO}_{2} \mathrm{R} 30$ line center. The transmitter is co-axially aligned to the receiver through bore-sighting. The IPDA receiver system is similar to the successfully demonstrated $2-\mu \mathrm{m} \quad \mathrm{CO}_{2}$ doublepulse IPDA lidar [3].

\subsection{Laser Transmitter Module Design}

The IPDA $2-\mu \mathrm{m}$ laser transmitter is based on Ho:Tm:YLF crystal with an emitted radiation wavelengths that cover strong $\mathrm{CO}_{2}$ absorption features. The long upper laser level lifetime of Tm and Ho provides the capability of generating three Q-switched pulses using a single pump pulse. The crystal is end pumped using $792 \mathrm{~nm}$ to excite Tm. The excited Tm pumps Ho which generates the 2$\mu \mathrm{m}$ emission. The co-doped approach has the advantage of providing close to 2 quantum efficiency in the Tm, and overall system simplicity [4]. Table 1 lists the main parameters of the IPDA laser transmitter. Figure 2 shows the temporal variation of the triple-pulse generation event. Stable pulse energy output is observed as shown in figure 3. Heat dissipation is essential for high intensity pump where high repetition rate operation is required. This required additional mitigation strategies for in laser head design.

A wavelength control unit provides three locked seeding wavelengths for the triple-pulse laser. The wavelength control consists of a single cw semiconductor laser diode [5]. The laser diode wavelength reference is locked to the $\mathrm{CO}_{2} \mathrm{R} 30$ line center through a gas cell. The three seeding wavelengths, shown in Figure 1, are generated by frequency offset with respect to the locked center line.

Custom designed electronics modules are used to synchronize and control timing between various transmitter components and IPDA receiver. The transmitter is housed in a sealed $67 \times 16.5 \times 26 \mathrm{~cm}^{3}$ enclosure purged with dry-air. The laser bench is temperature controlled to avoid thermal induced misalignment. All optical mounts are designed to be adjustable, lockable and flight hardened.

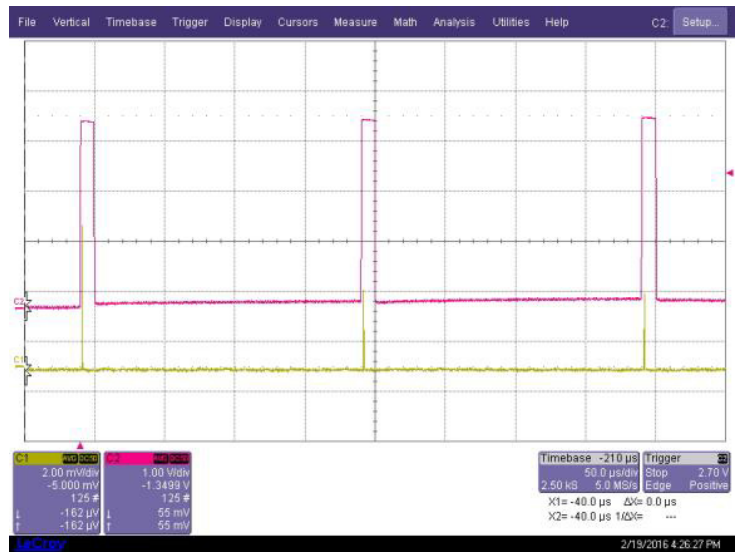

Figure 2 Single-shot temporal profile of the triplepulse generation (yellow) as compared to $Q$-switch timing (red). 


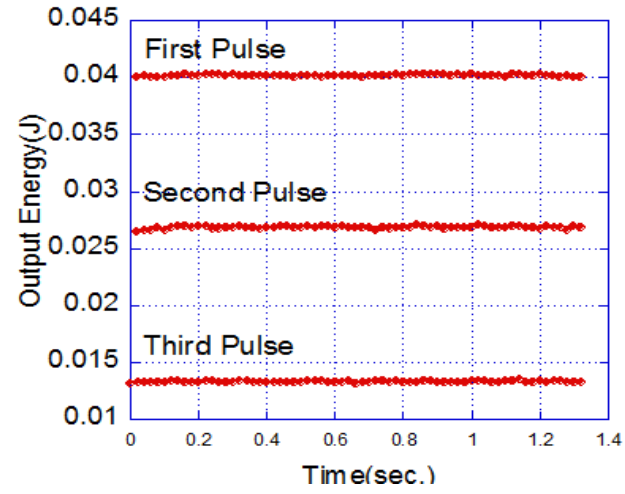

Figure 3 Shot by shot variation of the triple-pulse generated energies.

Table 1 IPDA transmitter parameters

\begin{tabular}{|lll|}
\hline Operating Wavelength & $\lambda_{1}$ & $2050.5094 \mathrm{~nm}$ \\
& $\lambda_{2}$ & $2051.0590 \mathrm{~nm}$ \\
& $\lambda_{3}$ & $2051.1915 \mathrm{~nm}$ \\
\hline Output Energy & $\lambda_{1}$ & $40 \mathrm{~mJ}$ \\
& $\lambda_{2}$ & $26 \mathrm{~mJ}$ \\
& $\lambda_{3}$ & $14 \mathrm{~mJ}$ \\
\hline Pulse Width & $\lambda_{1}$ & $22 \mathrm{~ns}$ \\
& $\lambda_{2}$ & $32 \mathrm{~ns}$ \\
& $\lambda_{3}$ & $60 \mathrm{~ns}$ \\
\hline Line Width & Transform Limit \\
\hline Beam Quality & \multicolumn{3}{c}{$<2$} \\
\hline Frequency Accuracy & \multicolumn{3}{c}{$<1 \mathrm{MHz}$} \\
\hline
\end{tabular}

\subsection{Receiver Design}

Figure 4 shows the main receiver components which includes a telescope, an aft-optics box and detection systems. A $0.4 \mathrm{~m}$ (F2.3) diameter aluminum, Newtonian telescope is custom designed for this lidar. The primary mirror is designed with hyperbolic curvature to minimize aberration. The secondary mirror is a two-surface flat, dichroic fused silica. The top surface turns the return radiation $90^{\circ}$ to the aft-optics and the bottom surface transmits the expanded laser beam down coaxially. The telescope field-of-view is $300 \mu \mathrm{rad}$ and focus spot size diameter is $300-\mu \mathrm{m}$. The telescope output radiation is coupled to a field-imaging aft-optics. The aft-optics collimates and splits the return radiation into two 90/10 detection channels.

The $90 \%$ return is focused onto InGaAs-based pin detector, similar to the double-pulse IPDA [3]. The other $10 \%$ is directed, using an optical fiber, to an advanced $\mathrm{HgCdTe}$ (MCT) electron-initiated

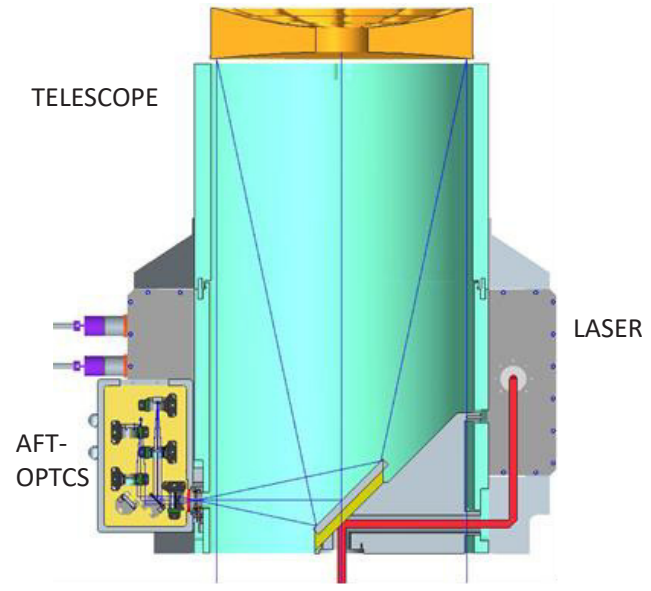

Figure 4 Schematic of the IPDA receiver with twochannel aft-optics for high-gain (90\%) InGaAs pin and low-gain (10\%) MCT e-APD detection systems.

avalanche photodiodes (e-APD), developed at DRS Technologies. This detector has a $4 \times 4$ pixel format with integrated trans-impedance amplifier (TIA) for each pixel. MCT e-APD detection system integration was conducted at NASA GSFC and includes cryogenic cooling, TIA buffering and summing electronics, and $2 \times 2$ pixel custom focusing optics. This detection channel exhibits high sensitivity with a typical $6 \mathrm{MHz}$ bandwidth noise-equivalent-power (NEP) of $1.4 \mathrm{fW} / \mathrm{Hz}^{1 / 2}$ per pixel. Operation of this detection system, in terms of pixel activation, bias voltage and gain selection is fully controlled with interfacing software [6].

\subsection{Data Acquisition and Processing}

IPDA data acquisition is based to two advanced 12-Bits, 1 GS/s, two-channel digitizers. One digitizer is dedicated for transmitted laser energy monitors. The other digitizer is dedicated for the two return signals channels. Both digitizers are enabled by the pump pules and triggered using the laser Q-switch driver. Several aspects of the digitizers were characterized and resulted in desirable performance in terms of dynamic range, overload recovery, linearity and noise. Total average noise was less than $1 \mathrm{mV}$. For a $2 \mathrm{~V}$ peakto-peak input range, this translates to a maximum signal-to-noise ratio of 2000. Figure 5 shows a snapshot of the data acquisition Graphical User Interface (GUI) during ground testing. The GUI shows the high and low gain channels return signals and one active energy monitor channel. Real-time data analysis will be tested during final phases of integration. 


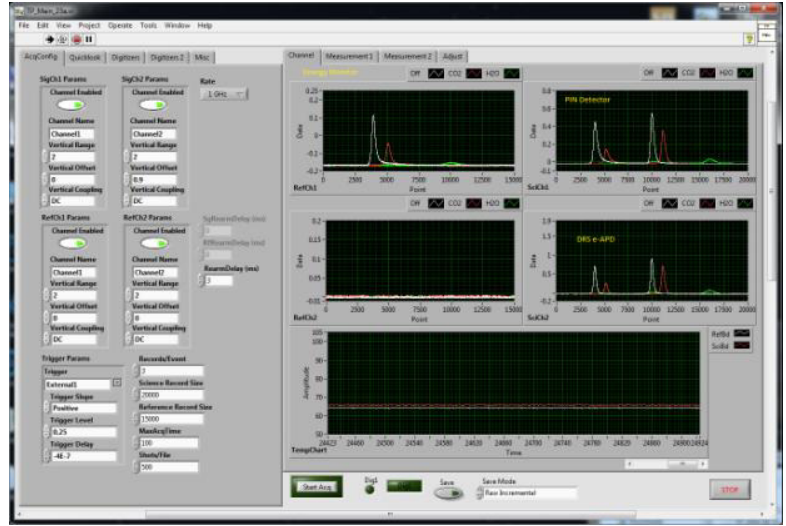

Figure 5 Data acquisition software GUI showing the triple-pulse energy monitor and return signals using InGaAs and MCT e-APD detection systems.

\section{VALIDATION PLANS}

The $2-\mu \mathrm{m}$ triple-pulse IPDA lidar validation is important to assess measurement capability of $\mathrm{XCO}_{2}$ and $\mathrm{XH}_{2} \mathrm{O}$. IPDA ground validation starts after integration in a mobile lidar laboratory. This facility enables IPDA horizontal measurement using calibrated targets and vertical measurements using clouds. Ground validation objectives are to check the IPDA lidar operational readiness and data processing algorithms before aircraft deployment.

The design of the 2- $\mu$ m IPDA lidar was set to meet the payload size, weight and power consumption requirements of the NASA-B200 aircraft. Initial engineering flights will focus on instrument operational reliability and initial performance testing. Later flights will focus on comparing $\mathrm{CO}_{2}$ and $\mathrm{H}_{2} \mathrm{O}$ measurements against correlative in-situ sensors and models. This includes evaluation of systematic and random errors. This will rely on onboard sensors as well as coordinated measurements with other independent sensors, such as NOAA air-sampling. Airborne validation will be planned to test the performance under different conditions including surface reflectivity changes; day and night background; clear, cloudy and broken cloud conditions; variable surface elevation; urban pollution; and plume detection.

\section{CONCLUSIONS}

A Novel IPDA lidar system that is capable of measuring both atmospheric $\mathrm{CO}_{2}$ and $\mathrm{H}_{2} \mathrm{O}$ independently and simultaneously from airborne platform is under development. All the different sub systems have been designed, built and characterized. IPDA integration and ground testing is planned to be completed soon. Airborne measurements are planned in conjunction with operation of other $\mathrm{CO}_{2}$ sensors such as NOAA tall tower network and airborne flask air-sampling for the validation of the IPDA. These evaluations will be conducted in various environment and ground reflectivity conditions such as vegetation, snow, sand and ocean during day and night. This IPDA lidar development opens a path toward spacebased active remote sensing.

\section{ACKNOWLEDGEMENTS}

This work was funded and supported by NASA Earth Science Technology Office.

\section{References}

[1] T. Refaat, U. Singh, J. Yu, M. Petros, S. Ismail, M. Kavaya, K. Davis, 2015: Evaluation of an airborne triple-pulsed $2 \mu \mathrm{m}$ IPDA lidar for simultaneous and independent atmospheric water vapor and carbon dioxide measurements, Appl. Opt. 54, 1387-1398.

[2] U. Singh, B. Walsh, J. Yu, M. Petros, M. Kavaya, T. Refaat, N. Barnes, 2015: Twenty years of Tm:Ho:YLF and LuLiF laser development for global wind and carbon dioxide active remote sensing, Opt. Mater. Exp. 5, 827-837.

[3] T. Refaat, U. Singh, M. Petros, R. Remus, J. Yu, 2015: Self-calibration and laser energy monitor validations for a double-pulsed $2-\mu \mathrm{m} \quad \mathrm{CO}_{2}$ integrated path differential absorption lidar application, Appl. Opt. 54, 7240-7251.

[4] B. Walsh, N. Barnes, M. Petros, J. Yu, U. Singh, 2004; Spectroscopy and modeling of solid state lanthanide lasers: Application to trivalent Tm and Ho in YLiF and LuLiF, J. Appl. Phys. 95, 32553271.

[5] M. Bagheri, G. Spiers, C. Frez, S. Forouhar, F. Aflatouni, 2015; Linewidth measurement of distributed-feedback semiconductor lasers operating near $2.05 \mu \mathrm{m}$, IEEE Phot. Tech. Let. 27, 1934-1937.

[6] X. Sun, J. Abshire, J. Beck, 2014: HgCdTe eAPD detector arrays with single photon sensitivity for space lidar applications, Proc. of SPIE 9114, 91140K. 